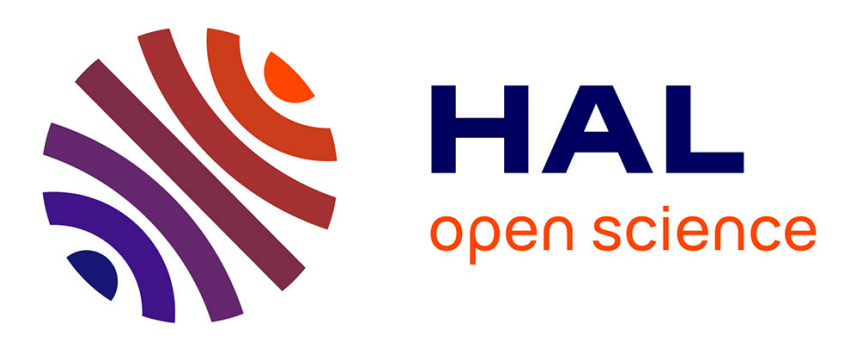

\title{
A Systemic Approach Integrating Driving Cycles for the Design of Hybrid Locomotives
}

Amine Jaafar, Bruno Sareni, Xavier Roboam

\section{To cite this version:}

Amine Jaafar, Bruno Sareni, Xavier Roboam. A Systemic Approach Integrating Driving Cycles for the Design of Hybrid Locomotives. IEEE Transactions on Vehicular Technology, 2013, vol. 62, pp.35413550. 10.1109/TVT.2013.2267099 . hal-00876675

\section{HAL Id: hal-00876675 \\ https://hal.science/hal-00876675}

Submitted on 25 Oct 2013

HAL is a multi-disciplinary open access archive for the deposit and dissemination of scientific research documents, whether they are published or not. The documents may come from teaching and research institutions in France or abroad, or from public or private research centers.
L'archive ouverte pluridisciplinaire HAL, est destinée au dépôt et à la diffusion de documents scientifiques de niveau recherche, publiés ou non, émanant des établissements d'enseignement et de recherche français ou étrangers, des laboratoires publics ou privés. 


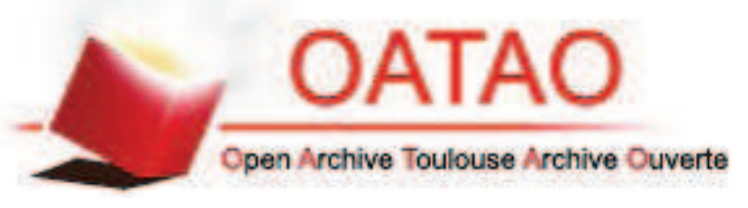

\section{Open Archive TOULOUSE Archive Ouverte (OATAO)}

OATAO is an open access repository that collects the work of Toulouse researchers and makes it freely available over the web where possible.

This is an author-deposited version published in : http://oatao.univ-toulouse.fr/ Eprints ID : 9802

To link to this article : DOI:10.1109/TVT.2013.2267099

URL : http://dx.doi.org/10.1109/TVT.2013.2267099

To cite this version Jaafar, Amine and Sareni, Bruno and Roboam, Xavier $A$ Systemic Approach Integrating Driving Cycles for the Design of Hybrid Locomotives. (2013) IEEE Transactions on Vehicular Technology, vol. 62 $\left(\mathrm{n}^{\circ}\right.$ 8). pp. 3541-3550. ISSN 0018-9545

Any correspondance concerning this service should be sent to the repository administrator: staff-oatao@,1istes-diff.inp-toulouse.fr 


\title{
A Systemic Approach Integrating Driving Cycles for the Design of Hybrid Locomotives
}

\author{
Amine Jaafar, Bruno Sareni, and Xavier Roboam
}

\begin{abstract}
Driving cycles are essential in hybrid locomotive design by conditioning their size and performance. This paper introduces a new systemic approach to hybrid locomotive design, taking real-world driving cycles into account. The proposed approach first exploits clustering analysis with the aim of identifying classes corresponding to particular sets of driving cycles. Then, a synthesis process of a reduced and representative profile from each class of driving cycles is presented. Both approaches are applied to the integrated optimal design of an autonomous hybrid (Diesel-electric) locomotive devoted to shunting and switching operations in nonelectrified areas.
\end{abstract}

Index Terms-Clustering analysis, driving cycles, evolutionary algorithms, hybrid electrical vehicles (HEVs), hybrid locomotives, integrated design, optimization.

\section{INTRODUCTION}

$\mathbf{T}$ HE integration of driving cycles constitutes a key step in hybrid electrical vehicle (HEV) analysis and design. HEV efficiency in terms of fuel consumption, energy range, and battery health strongly depends on the way HEVs are used. Therefore, the study of driving cycles and their impact on HEV performance are fundamental. The most commonly used design approach to integrate driving missions and assess HEV efficiency consists in using standard cycles. These cycles can be found either for automotive [1]-[4] or for locomotive [5] applications. However, the use of these cycles in HEV design has been criticized since they are not truly representative of real driving conditions, specifically depending on the effect of the environment (i.e., road traffic, signalization, and driver's driving style [6], [7]). The main difficulty in finding representative profiles for driving cycles is related to their heterogeneity. To overcome this problem and facilitate the identification of more realistic profiles in compliance with driving conditions, statistical studies have been performed from real-world driving cycles issued from data collected on vehicles (see [7]-[12] for example). In this context, the clustering analysis of real-world cycles has been investigated, leading to the construction of new reference cycles obtained from the concatenation of typical

The authors are with the Laboratory on Plasma and Conversion of Energy (LAPLACE), University of Toulouse, 31071 Toulouse, France (e-mail: jaafar@ laplace.univ-tlse.fr; sareni@laplace.univ-tlse.fr; roboam@laplace.univ-tlse.fr).

Digital Object Identifier 10.1109/TVT.2013.2267099 driving patterns belonging to different classes (urban, suburb, rural, or motorway cycles). Other approaches consist in the generation of driving cycles with stochastic models aiming at reproducing real-world data [13]-[20]. In particular, synthesis methods using Markov chains based on transition probability matrices (TPMs) extracted from data sets of driving cycles have been developed in [15]-[20]. In these methods, representative profiles are constructed from TPMs fulfilling driving distances and multiple statistical criteria such as mean velocity, standard deviation of velocity, minimum, maximum, and average acceleration, etc.

Even if the problem of driving cycle integration has been addressed in the frame of automotive HEV design, it can be generalized to any kind of embedded systems. In this paper, we exclusively consider the case of an autonomous hybrid (Diesel-electric) locomotive devoted to shunting and switching operations. Contrary to HEVs, for which driving cycles are generally defined by the vehicle speed versus time, the locomotive missions will be described as the total load power needed versus time in this paper (i.e., including all load requirements for traction and auxiliaries). Nevertheless, the methods investigated in this paper can be extended to other systems and other representations of driving cycles with ease.

The main contribution of this paper resides in the joint exploitation of clustering analysis and of a new driving cycle synthesis process for HEV design through a systemic approach. Clustering analysis aims at investigating the interest of designing an HEV propulsion system per classes of driving cycles in comparison with one unique system devoted to all classes. A driving cycle synthesis process is then used to determine representative profiles of each class. This process differs from those presented in the literature and constitutes the second contribution of this paper. It consists in finding a fictitious profile that fulfills specific indicators related to driving cycle properties, conditioning HEV sizing and efficiency. The profile is constructed by aggregating elementary segments parameterized in amplitude and duration. The number of segments and their parameters are determined by a niching genetic algorithm (GA) so that the generated profile fulfills all indicators. This process can be applied to the determination of representative profiles of sets of driving cycles or to the simplification of driving cycles of large duration.

This paper is organized as follows. Section II briefly presents the context of HEV design and the indicators related to driving cycle properties, affecting HEV sizing and performance. Section III deals with the clustering analysis of driving cycles in relation to the defined indicators. Section IV tackles the synthesis process of representative driving cycles based on a niching 


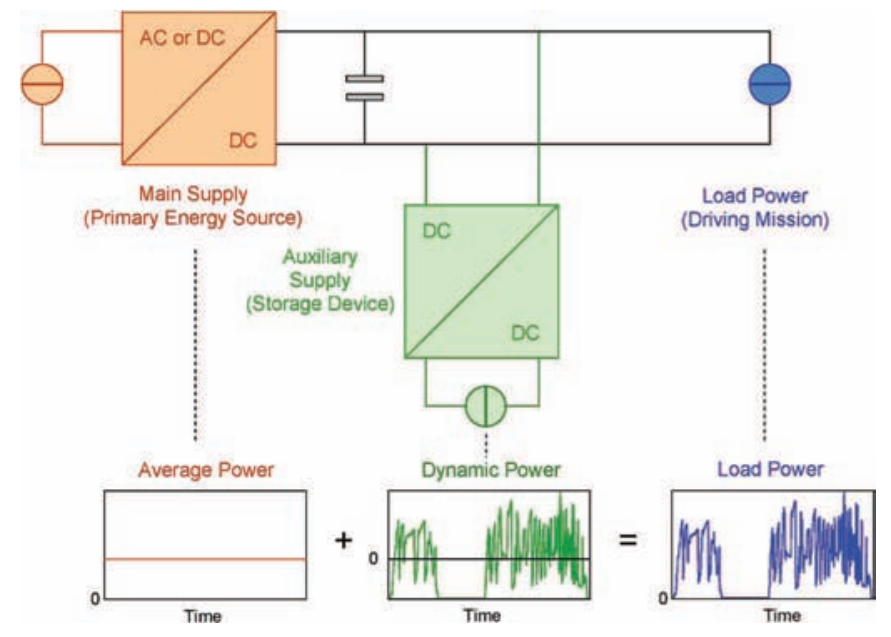

Fig. 1. Energy management strategy.

GA. Then, the interest of a systemic approach combining clustering analysis and synthesis of representative driving cycles is shown in Section $\mathrm{V}$, which investigates the design of hybrid locomotives for shunting and switching operations in nonelectrified areas. Finally, conclusions are drawn in Section VI.

\section{Design Indicators Related to Driving CyCles IN HYBRID ARCHITECTURES}

Here, we introduce different design indicators correlated with the sizing or efficiency of hybrid architectures, which are directly related to the driving cycles. In the following, these indicators will be used to classify and simplify driving cycles in the context of integrated design approaches aiming at optimizing architectures, sizing, and energy management [21].

\section{A. First Set of Indicators Related to the System Sizing}

The first three indicators $\left(P_{\max }, P_{\mathrm{av}}\right.$, and $\left.E_{u}\right)$ are relative to the energy issue and are linked to the propulsion system sizing. Indeed, the design of power sources in hybrid architectures strongly depends on the way that sources cooperate to fulfill the driving cycles. In these systems, a possible energy management consists in providing the average part of the load power by a primary energy source [22], [23] (see Fig. 1). The remaining power (i.e., the fluctuant part) is devoted to a storage system (i.e., the auxiliary source). With this particular power dispatching, the sizing of the main supply essentially depends on the average load power $P_{\text {av }}$ defined as

$$
P_{\mathrm{av}}=\frac{1}{\Delta T} \int_{0}^{\Delta T} P_{\text {load }}(t) d t
$$

where $\Delta T$ denotes the driving cycle duration, and $P_{\text {load }}$ represents the load power required by the driving cycle. Furthermore, the sizing of the storage device can be characterized in terms of power, according to the maximal power imposed to this auxiliary supply, i.e., $P_{\max }-P_{\mathrm{av}}$, where $P_{\max }$ represents the maximal load power related to the driving cycle. It also depends on the maximum energy quantity $E_{u}$ transferred to the storage device. This energy can be computed as

$$
E_{u}=\max _{t \in[0, \Delta T]}\left(E_{s}(t)\right)-\min _{t \in[0, \Delta T]}\left(E_{s}(t)\right)
$$
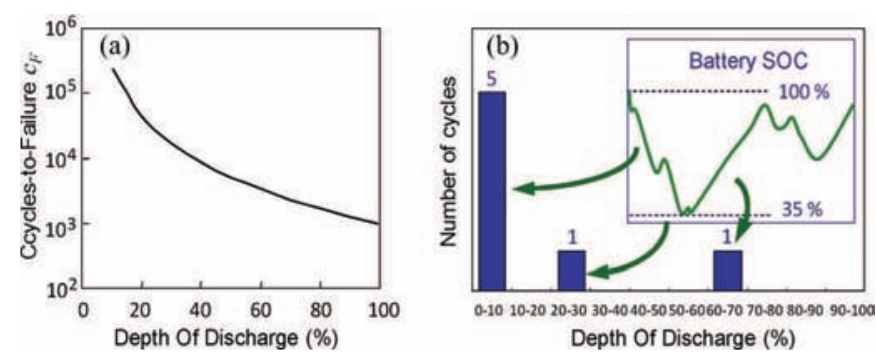

Fig. 2. Illustration of the storage cyclability estimation. (a) Cycle-to-failure characteristic. (b) Number of cycle calculation versus DOD levels.

where storage energy level $E_{s}$ is defined as follows:

$$
E_{s}(t)=-\int_{0}^{t}\left(P_{\text {load }}(\tau)-P_{\mathrm{av}}\right) d \tau
$$

It should be noted that $E_{s}(t)$ is a saturated integral with zero as the upper limit so that the storage is only sized in discharge mode to avoid its oversizing during wide charge phases.

\section{B. Second Set of Indicators Related to the System Performance}

The first indicator of this second set is the cumulative distribution function (cdf), which is associated with the load power required by the driving profile. This function is defined on the space of the load power distribution and represents the system probability to operate at a power level less than or equal to a load power value.

Finally, the last indicator considered in this paper is related to the cyclability of the storage system. This indicator is essential in HEV design since it provides information on the storage lifetime. Therefore, we consider in this paper the total number of cycles $N_{c_{-} \text {tot }}$ imposed to the storage during the driving cycle. This indicator is related to the storage state of charge (SOC) evolution and to the number of cycles to failure $c_{F}$ [24], [25] defined as a function of the depth of discharge (DOD), which is specified in percentage [see Fig. 2(a)]. Considering the number of cycles to failure for DOD $=100 \%$ as a reference, we can express a "cycle weight" $\omega_{\text {cycle }}$ for lower DODs as [26]

$$
\omega_{\text {cycle }}(\mathrm{DOD})=\frac{c_{F}(100 \%)}{c_{F}(\mathrm{DOD})} \text {. }
$$

This weight evaluates the effect of a cycle at a given DOD with regard to a cycle at full DOD. Since the storage SOC evolution during a driving cycle consists in various cycles with different DODs, the total number of cycles $N_{c_{-} \text {tot }}$ is computed as follows:

$$
N_{c \_ \text {tot }}=\sum_{\text {DOD }} \omega_{\text {cycle }}(\mathrm{DOD}) \times N_{\text {cycle }}(\mathrm{DOD})
$$

where $N_{\text {cycle }}(\mathrm{DOD})$ denotes the number of cycles at a particular DOD. In practice, the DOD range is divided into equidistant intervals (typically, ten intervals), and the number of cycles in each interval is determined with the rainflow counting method [27], leading to a discretization of (3). This process is shown in Fig. 2(b). We point out that the $N_{c \_t}$ indicator depends on the storage nature through the cycle-to-failure characteristics. 
This highlights a coupling between the system features (i.e., the type of storage) and the system environment (here, the driving cycle).

In the following, we will consider as storage device the Hoppecke FNC1502HRNiCd battery cells [28] used in nominal conditions (i.e., temperature between $30{ }^{\circ} \mathrm{C}-40{ }^{\circ} \mathrm{C}$, which are charged at $C_{5}$ and discharged at $2 C_{5}$ ). In that case, the cycleto-failure curve plotted in Fig. 2(a) can be approximated as

$$
c_{F}(\mathrm{DOD})=966 \times \mathrm{DOD}^{-2.37}
$$

\section{Clustering Analysis of Driving CyCles}

From the system point of view, the classification of driving cycles according to pertinent indicators with regard to design criteria and constraints is a part of a set of decision-making tools and constitutes a ridge phase, which is essential to the design process. Indeed, it must enable designers to evaluate the interest in a device that is specifically optimized for a given class, relative to the driving cycles, and this is compared with a device capable of simultaneously satisfying a set of classes. In other words, taking the well-known example of the car, "what do we gain by classifying and segmenting a vehicle range (urban, road, off-road, etc.) from the point of view of the cost/ performance ratio and with regard to usage and its occurrences?" Classifying or segmenting may thus enable a notable improvement in certain criteria, such as the energy efficiency of the system. This is, for example, the case when, regarding a classification according to energy indicators, the segments or classes obtained are different from the commercial segmentation or usage of the system.

In [29], a niching GA has been developed for the classification of driving cycles. This algorithm is based on the use of restricted tournament selection (RTS) [30] and a self-adaptive recombination technique [31], with the objective of maximizing the silhouette index [32] of the driving cycle data sets. In the following, we present an application of this algorithm to benchmark railway profile (railway driving cycle) classifications.

This benchmark, consisting of a set of 105 railway power profiles, is used to show the interest of clustering analysis in the context of hybrid system design. This set is composed of three subsets of profiles devoted to three different French railway systems: the $\mathrm{BB} 63000$ old freight locomotive, the $\mathrm{BB}$ 460000 fret service locomotive, and the auxiliary supply for TGV (i.e., the French high-speed train). These systems have been considered to put forward the interest of the classification approach based on purely energy indicators. All profiles, which are represented by the load power demand as a function of time, are characterized according to the triplet of energy-based design indicators $\left(P_{\mathrm{av}}, P_{\max }\right.$, and $\left.E_{u}\right)$ aforementioned. The energy management strategy is described in Fig. 1. All profiles are represented versus the design indicators in Fig. 3(a). The centroid of each subset is also indicated with a black mark. In Fig. 3(b), the classification of the profiles obtained from the RTS runs after 500 generations is plotted. It is shown that the niching GA is capable of finding the correct partitioning of data by identifying three distinct clusters. The difference between both partitioning is only of $12 \%$ (i.e., 13 profiles over 105). Note that

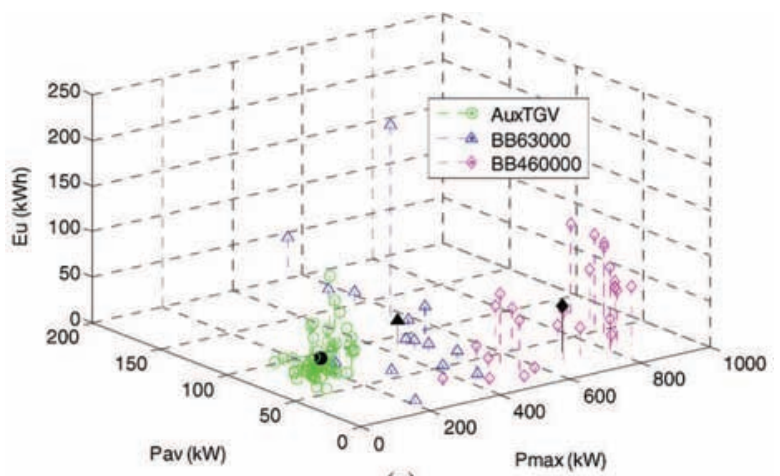

(a)

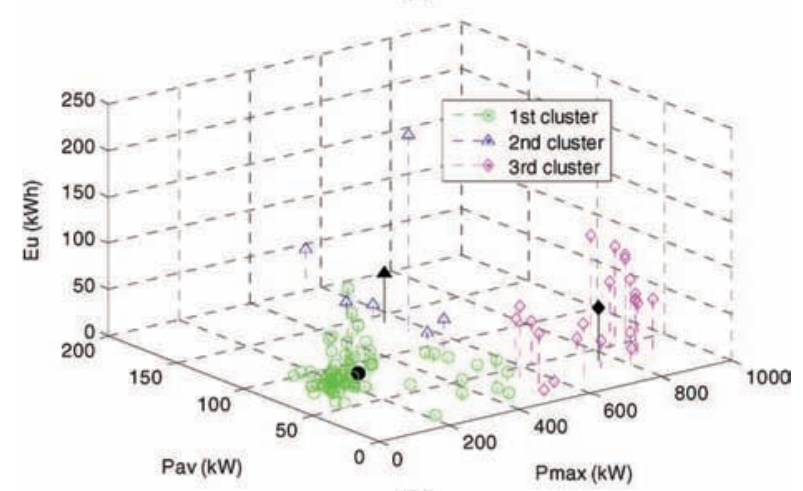

(b)

Fig. 3. Profile classification of three railway systems. (a) Initial distribution of profiles. (b) Classification result.

the set of 105 profiles based on three different subsets of application (BB 63000, BB 460000, and TGV Aux) may present some similarities in terms of power/energy design indicators so that clustering profiles issued from different subsets may be energetically coherent. Thus, obtaining some differences between reference and RTS-based clustering is not necessary due to the niching GA convergence. All data are globally well classified, except elements located in the region covered by the three subsets. In this particular region of low power and energy, all profiles can be performed by the three hybrid supplies. Therefore, the assignment by the RTS of elements to the closest and most densely populated cluster (i.e., the cluster corresponding to TGV Aux driving profiles) is not surprising. This also explains the greater deviation of the cluster centroid relative to BB63 000 data. This cluster is more sensitive to partitioning errors because of its small size. Moreover, both other cluster centroid positions are relatively unchanged by the RTS partitioning due to their larger size. These results also show the relevance of the proposed triplet for clustering analysis in the context of hybrid supply design.

\section{Synthesis PRocess of ReducED AND REPRESENTATIVE REAL-WORLD DRIVING CYCLES}

\section{A. Principle}

Beyond the classification methodology of the driving cycles presented in Section III, the next issue is to know how to best integrate the set of profiles from one class into a systemic design approach. In other words, we are looking to represent the information content of one set of profiles using a single 


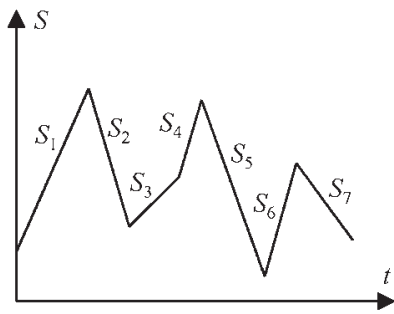

(a)

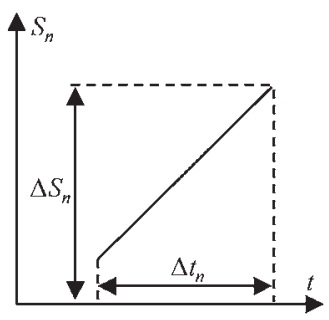

(b)
Fig. 4. Principle of the profile generation. (a) Profile generated by segment. (b) Pattern parameters.

and more compact, but representatively fictitious profile, to minimize computation costs within a system design process, particularly in the context of integrated design by optimization [21]. The fictitious profile is obtained by aggregating elementary segments, as shown in Fig. 4. Each segment is characterized by its amplitude $\Delta S_{n}\left(\Delta S_{\min } \leq \Delta S_{n} \leq \Delta S_{\max }\right)$ and its duration $\Delta t_{n}\left(0 \leq \Delta t_{n} \leq \Delta t_{\text {compact }}\right)$. Finding a compact fictitious profile consists in finding all segment parameters so that the generated profile fulfills all target indicators on the reduced duration $\Delta t_{\text {compact. }}$. This results in solving an inverse problem with $2 N$ parameters, where $N$ denotes the number of segments in the compact profile. This can be done using evolutionary algorithms and, particularly, with the clearing method [33], which is well suited to treat this kind of problem with high dimensionality and high multimodality. It should be also noted that the number $N$ of segments is optimized through a self-adaptive procedure [34]. The profile synthesis by an optimization process is given in Fig. 5. The first stage consists of building profile $S(t)$ from the chromosome generated by the evolutionary algorithm, using the concatenation of $N$ elementary segments. A time-scaling step is performed after the profile generation to fulfill the constraint related to the time duration, i.e., $\Sigma \Delta t_{n}=\Delta t_{\text {compact }}$. The duration $\Delta t_{\text {compact }}$ of the obtained cycle is considered to be a problem input. Although we are taking care to ensure that the synthesized profile is as compact as possible, the choice of its duration must check certain constraints relative to the design indicators, as defined in Section II. In the following stage, we compute the profile indicators $I_{j}$ (obtained from the synthesized profile), which are then compared with the reference indicators $I_{\text {jref }}$ (obtained from the reference set of profiles). It enables error function $\varepsilon$ (the function to be minimized using the evolutionary algorithm), which is expressed as

$$
\varepsilon=\sum_{j}\left(\frac{I_{j}-I_{\mathrm{jref}}}{I_{\mathrm{jref}}}\right)^{2}
$$

to be evaluated. This function is defined as the sum of quadratic scaled errors between reference and synthesized profile indicators.

\section{B. Application on Railway Driving Cycles}

Here, we study an example of ten railway driving cycles (see the Appendix) with the same duration (i.e., $4 \mathrm{~h}$ ) used for the hybridization of the Diesel locomotive BB 63000 . The architecture and the energy management strategy are in

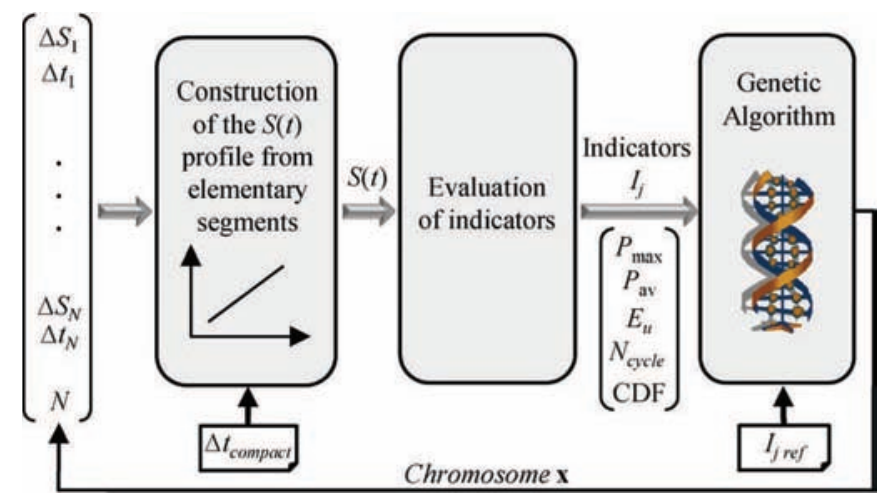

Fig. 5. Synthesis process of representative profiles.

compliance with Fig. 1. The main supply is a Diesel engine, and the auxiliary supply is composed of $\mathrm{Ni}-\mathrm{Cd}$ accumulator batteries (see Section V). The different driving cycles presented in the Appendix were assumed to be applied to the locomotive with the same occurrence. Moreover, batteries are supposed to be recharged after each 4-h driving cycle. Consequently, the reference indicators are chosen as follows.

- The average reference power $P_{\text {av ref }}$ is set at the average concatenation value for all cycles. We remind the reader that this power value corresponds to the Diesel engine sizing, which is a device for which consumption and "pollution" are optimum when this latter operates at its nominal power [23], [26].

- $P_{\text {maxref and }} E_{u \text { ref }}$ indicators are set at the more constraining values for all of the ten driving cycles, i.e., $P_{\max \text { ref }}=\max P_{\max }(i)$ and $E_{u \text { ref }}=\max E_{u}(i)$, where $i$ denotes the driving cycle index $(i=1, \ldots, 10)$. This enables us to guarantee that the system being designed will satisfy all driving cycles.

- The performance and lifetime indicators are considered to be average. The choice of useful reference energy $E_{u \text { ref }}$ enables the storage size to be determined, and as a consequence, we are able to estimate the number of cycles consumed for each driving cycles. The number of reference cycles $N_{c \_ \text {tot ref }}$ is thus determined by the average value of the cycle number per hour across all profiles. For statistical reference indicator $I_{\text {stat ref, we }}$ consider the cdf associated with the concatenation of all cycles.

Note that the nature of the design indicators imposes substantial minimum times. This refers most particularly to the useful energy indicator or the number of cycles that are closely coupled with the profile duration. The representative railway driving profile is obtained through the concatenation of 148 segments (see Fig. 6). We give in Table I the values of sizing and performance indicators of this profile in comparison with the reference values. Note that the statistic error $\varepsilon_{\text {stat }}$ is defined as the mean square error, which is computed over 100 equally spaced points, between both cdfs relative to the power of the driving cycles, i.e.,

$$
\varepsilon_{\text {stat }}=\frac{1}{100} \times \sum_{i=1}^{100}\left(\frac{\operatorname{cdf}(i)-\operatorname{cdf}_{\mathrm{ref}}(i)}{\operatorname{cdf}(i)}\right)^{2} .
$$




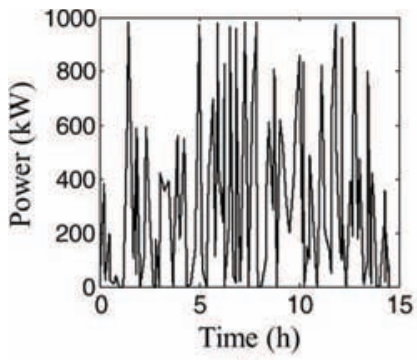

(a)

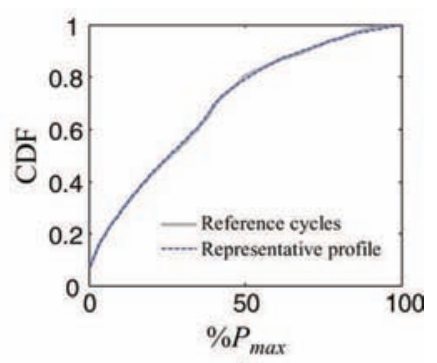

(b)
Fig. 6. Result of the compact profile synthesis process on ten driving cycles. (a) Representative driving profile. (b) Distribution functions.

TABLE I

Characterization Indicators of the Representative Profile

\begin{tabular}{cccc}
\hline \hline & Reference indicators & $\begin{array}{c}\text { Representative } \\
\text { profile indicators }\end{array}$ & Error $(\%)$ \\
\hline$P_{\max }(\mathrm{kW})$ & 980.5 & 980.5 & $<10^{-2}$ \\
$P_{\mathrm{av}}(\mathrm{kW})$ & 300 & 300 & $<10^{-2}$ \\
$E_{u}(\mathrm{kWh})$ & 569.3 & 569.3 & $<10^{-2}$ \\
$N_{\text {c tot }}$ & 0.04 & 0.04 & $<10^{-2}$ \\
$\varepsilon_{\text {stat }}$ & - & - & 0.8 \\
\hline \hline
\end{tabular}

The results show that our signal synthesis approach performs well and is capable of finding a profile shape representing the whole set of driving cycles. It should be noted that the "fictitious" profile duration is about $14.5 \mathrm{~h}$. In comparison with the global duration of the ten profiles (i.e., $40 \mathrm{~h}$ ), the profile duration has been reduced by 2.8 . Consequently, in a design optimization process such as in [35], the simulation of any hybrid electric system will also be reduced.

\section{INTEGRATEd Optimal DESIGN OF A HybRid LOCOMOTIVE FROM REAL-WORLD DRIVING CYCLES}

Here, we are proposing to show the complete process for a systemic design approach. Starting with the classification of real profiles (see Section III), the profile synthesis process (see Section IV) based on a set of railway driving cycles is used to complete the integrated design by optimization of the railway hybrid system. The idea is to design a hybrid locomotive optimized for each profile class and to compare the cost of annual ownership of the devices obtained, with the design of a single locomotive capable of satisfying all profile classes at once. This general approach to system design is founded on a reference database corresponding to an example using ten railway driving cycles with iso-times ( $4 \mathrm{~h}$ per profile). We assume that the storage SOC of Ni-Cd batteries is reset to $100 \%$ after each 4-h cycle sequence. In Fig. 7, we show the various stages of the proposed comparative study.

\section{A. Hybrid Locomotive Model}

1) Power Flow Model: The power flow model determines the energetic characteristics of the locomotive power sources i.e., power $P$, energy $E$, and the SOC for the storage elements. Considering a given power profile $P_{M}$, an energy management controller provides power reference values for the Diesel engine $\left(P_{\mathrm{DEref}}\right)$ and the batteries $\left(P_{\mathrm{BTref}}\right)$. These references are

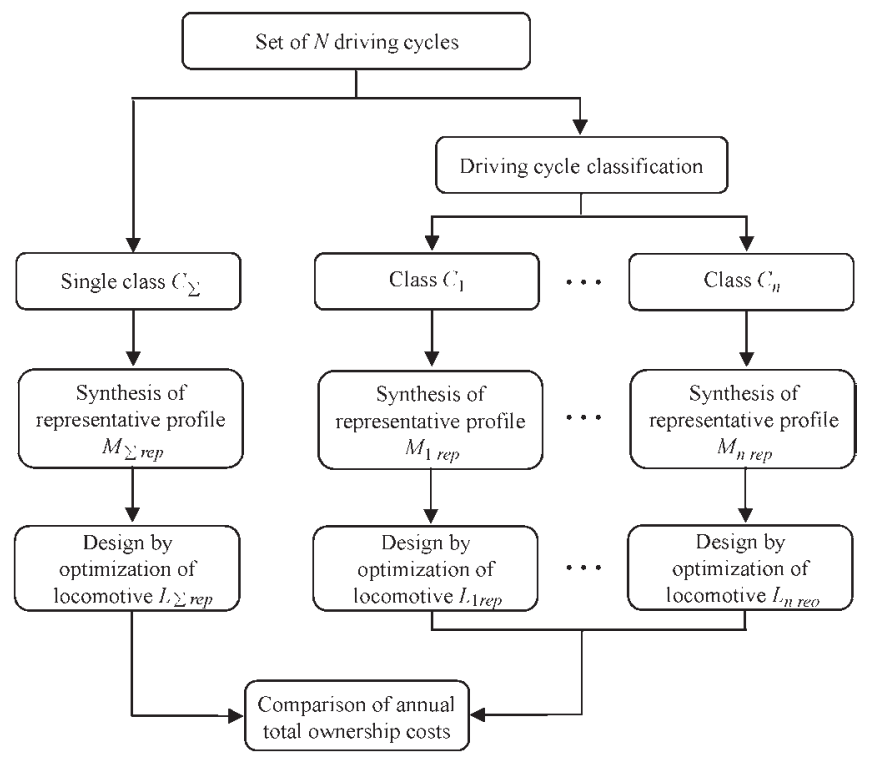

Fig. 7. General system approach, from classification to optimal design.

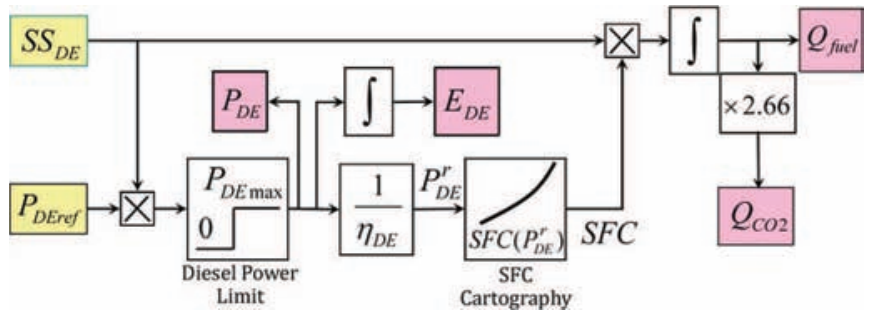

Fig. 8. Power flow model of the Diesel engine.

obtained according to the management strategy of Fig. 1. The power flow model of the Diesel engine is given in Fig. 8. It allows us to obtain power reference $P_{\mathrm{DEref}}$ and a start/stop control, the Diesel engine power $P_{\mathrm{DE}}$, the corresponding energy $E_{\mathrm{DE}}$, the quantity of fuel consumed $Q_{\text {fuel }}$, and the corresponding quantity of emitted carbon dioxide $Q_{\mathrm{CO}_{2}}$. The parameters of this model are the converter efficiency associated with the Diesel engine (typically, $\eta_{\mathrm{DE}}=96 \%$ ), the Diesel power limit $P_{\mathrm{DE} \text { max }}$, and the specific fuel consumption (SFC) characteristic. This characteristic has been extrapolated with a fifthorder polynomial as a function of the Diesel engine power as follows [26]:

$$
\mathrm{SFC}\left(P_{\mathrm{DE}}\right)=\mathrm{SFC}_{N} \sum_{i=1}^{5} b_{i}\left(\frac{P_{\mathrm{DE}}}{P_{\mathrm{DEN}}}\right)
$$

where the polynomial coefficients are $b_{0}=1.94, b_{1}=-6.44$, $b_{2}=18.57, b_{3}=-27.22, b_{4}=19.72$, and $b_{5}=1.94 . P_{\mathrm{DEN}}$ denotes the nominal power of the Diesel engine, and $\mathrm{SFC}_{N}$ represents the SFC at this power estimated at $202.45 \mathrm{~g} / \mathrm{kW}$. The previous relation has been validated for three Diesel engines of the Fiat Powertrain Technologies Group [36], i.e., the N67 TM2A with $125 \mathrm{~kW}$, the C78 TE2ES with $236 \mathrm{~kW}$, and the C13 TE2S with $335 \mathrm{~kW}$. It should be noted that the SFC is at the minimum when the Diesel engine operates at its nominal power $P_{\mathrm{DEN}}$. Therefore, the energy management controller tends to maintain the Diesel engine power reference 


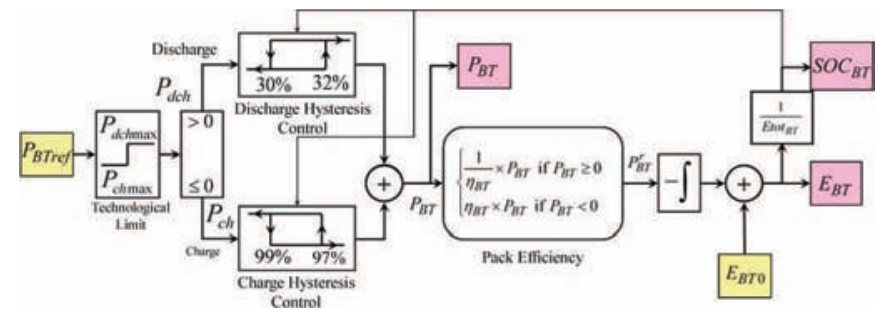

Fig. 9. Battery power flow model.

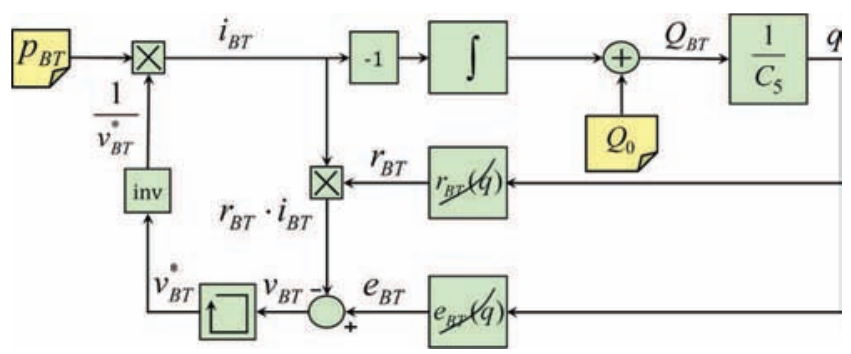

Fig. 10. Battery cell electric model.

close to this power. Note also that the maximal Diesel engine power is considered $10 \%$ higher than the nominal power. The quantity of $\mathrm{CO}_{2}$ emitted (in kilograms per liter) is directly proportional to the fuel quantity consumed and is estimated as follows [37]:

$$
Q_{\mathrm{CO}_{2}}=2.66 \times Q_{\text {fuel }} .
$$

The battery power flow model is given in Fig. 9. In this model, the storage power $P_{\mathrm{BT}}$, the corresponding energy $E_{\mathrm{BT}}$, and the associated $\mathrm{SOC} \mathrm{SOC}_{\mathrm{BT}}$ are computed from the initial energetic capacity $E_{\mathrm{BT} 0}$, the reference power resulting from the energy management controller $P_{\mathrm{BT} 0}$, the maximum discharge power $P_{\text {dchmax }}$ and the maximum charge power $P_{\text {chmax }}$ of the battery pack, and the efficiency $\eta_{\mathrm{BT}}$. Note that the total energetic capacity of a pack depends on the total number of cells and on the capacity of each cell.

2) Electric Model: Beyond the power flow model, which only specifies power and energy transfers, one further step is achieved at the electric model level, which provides voltages and currents. An $R C$ electric model is used to obtain the electrical variables (current and voltage) in a battery cell (see Fig. 10).

Technological data values corresponding to Hoppecke FNC1502HR battery cells of 135-Ah capacity $\left(C_{5}=135 \mathrm{Ah}\right)$ are considered in these models [28]. The battery resistance $r_{\mathrm{BT}}$ and its electromotive force $e_{\mathrm{BT}}$ are interpolated from the manufacturer data as a function of the cell $\operatorname{SOC} q$, i.e.,

$$
\left\{\begin{array}{l}
r_{\mathrm{BT}}=2.83-12.88 q+24.88 q^{2}-20.83 q^{3}+6.28 q^{4} \\
e_{\mathrm{BT}}=0.99+1.06 q-1.82 q^{2}+1.11 q^{3} .
\end{array}\right.
$$

As shown in Fig. 10, the current and voltage in the cell are computed from the cell power $p_{\mathrm{BT}}$. This power can be obtained from the global power of the pack $P_{\mathrm{BT}}$. resulting from the power flow model, i.e.,

$$
p_{\mathrm{BT}}=P_{\mathrm{BT}} /\left(\mathrm{NP}_{\mathrm{BT}} \times \mathrm{NS}_{\mathrm{BT}}\right)
$$

where $\mathrm{NS}_{\mathrm{BT}}$ and $\mathrm{NP}_{\mathrm{BT}}$ denote the number of battery cells in series and the associated number of branches in parallel, respectively.

3) Geometric Model: From the data provided by manufacturers, the volume in square meters of the Diesel engine can be expressed in terms of its nominal power $P_{\mathrm{DEN}}$ in Watts using the following relation:

$$
\Omega_{\mathrm{DE}}=3 \times 10^{-5} P_{\mathrm{DEN}}+0.09 .
$$

The battery volume, taking into account the cooling systems and associated electronic modules (such as charge state balancing and thermal control), is given by the following:

$$
\Omega_{\mathrm{BT}}=\lambda_{\mathrm{BT}} \times \mathrm{NP}_{\mathrm{BT}} \times \mathrm{NS}_{\mathrm{BT}} \times \Omega_{\mathrm{BT} 0}
$$

where $\Omega_{\mathrm{BT} 0}=4.33 \times 10^{-3} \mathrm{~m}^{3}$, and $\lambda_{\mathrm{BT}}=1.8$ represents the assembly coefficient, which considers intercellular spaces, electronic modules, and cooling systems.

4) Battery Lifetime Model: The battery lifetime $\mathrm{LFT}_{\mathrm{BT}}$ is directly related to the number of battery cycles consumed during the railway profile. It is expressed by the product of the cycle number consumed by each cell $N_{c_{-} \text {tot }}$ and the number of cells in series $\mathrm{NS}_{\mathrm{BT}}$ and in parallel $\mathrm{NP}_{\mathrm{BT}}$, i.e.,

$$
\mathrm{LFT}_{\mathrm{BT}}=\mathrm{NP}_{\mathrm{BT}} \times \mathrm{NS}_{\mathrm{BT}} \times N_{c_{-} \text {tot }} .
$$

5) Cost Model: Similar to the geometric model, the cost model uses empiric relations derived from manufacturer data to evaluate the cost of each energetic source embedded in the locomotive. The global cost in euros of the Diesel engine $C_{\mathrm{DE}}$, including its installation, can be interpolated by a linear function versus the nominal power, i.e.,

$$
C_{\mathrm{DE}}[k €]=0.28 \times P_{\mathrm{DEN}}+14.5 \text {. }
$$

To take account of the Diesel engine costs during the locomotive exploitation (including repairs and maintenance), the previous relation has been modified. It has been estimated by the French National Railways Company (SNCF) that the Diesel engine cost over ten years is in, average, three times higher than the purchase cost [35]. Therefore, the previous relation can be modified as follows:

$$
C_{\mathrm{DE}}[k \in / \mathrm{yr}]=\frac{3}{10}\left(0.28 \times P_{\mathrm{DEN}}+14.5\right) .
$$

The cost of the battery cells is calculated from the cycle cost, which allows taking account of purchase costs (including installation costs) and maintenance costs (directly related to the battery lifetime). A battery deep cycle (100\% of DOD) cost has been estimated to $0.122 €$. By considering the $\mathrm{LFT}_{\mathrm{BT}}$ stress estimator that evaluates the total number of cycles for the battery pack on a particular railway profile, the battery cost per year $C_{\mathrm{BT}}$ can be expressed as

$$
C_{\mathrm{BT}}[k \in / \mathrm{yr}]=0.122 \times 10^{-3} \times \mathrm{LFT}_{\mathrm{BT}} \times \frac{\Delta \tau_{\mathrm{yr}}}{\Delta \tau}
$$

where $\Delta \tau_{\mathrm{yr}}$ represents the locomotive exploitation in one year (typically $8 \mathrm{~h} /$ day), and $\Delta \tau$ denotes the total railway profile 
TABLE II

HyBRID LOCOMOTIVE DESIGN VARIABLES

\begin{tabular}{ccc}
\hline \hline Design Variable & Nature & Bounds \\
\hline Number of battery cells in series & Discrete & $0 \leq \mathrm{NS}_{\mathrm{BT}} \leq 456$ \\
Number of battery blocks in parallel & Discrete & $0 \leq \mathrm{NP}_{\mathrm{BT}} \leq 32$ \\
DC bus voltage [V] & Continuous & $50 \leq \mathrm{V}_{\mathrm{bus}} \leq 650$ \\
Converter switching frequency $[\mathrm{kHz}]$ & Continuous & $0 \leq \mathrm{F}_{\mathrm{SW}} \leq 10$ \\
\hline \hline
\end{tabular}

duration. Finally, with a Diesel fuel cost of about $1.35 € / 1$, the global cost per year can be estimated as

$$
C_{\text {fuel }}[k € / \mathrm{yr}]=1.35 \times 10^{-3} \times Q_{\text {fuel }} \times \frac{\Delta \tau_{\mathrm{yr}}}{\Delta \tau} .
$$

\section{B. Optimization Process}

1) Optimization Parameters: The design variables and their associated bound are shown in Table II.

2) Optimization Constraints: Four inequality constraints that are classically formulated in terms of minimization (i.e., $g_{i} \leq 0$ ) have to be fulfilled to ensure the locomotive feasibility. These constraints can be separated into two groups. The first three constraints $\left(g_{1}, g_{2}\right.$, and $\left.g_{3}\right)$ do not require the locomotive simulation on its driving cycle and are qualified as presimulating constraint. On the contrary, the last constraint $\left(g_{4}\right)$ is a postsimulating constraint, which can be only evaluated from the driving cycle simulation. With the aim of improving the CPU time related to the optimization step, this constraint is computed only if all presimulating constraints are fulfilled. Otherwise, it receives the maximum penalty (i.e., $g_{4} \rightarrow \infty$ ).

- The first constraint $g_{1}$ verifies that the volume available for energy sources is lower than $32 \mathrm{~m}^{3}$, i.e.,

$$
g_{1}=\Omega_{\mathrm{BT}}+\Omega_{\mathrm{DE}}-32 \leq 0
$$

without considering at this stage the static converter volume associated with battery blocks.

- The second constraint $g_{2}$ is related to the minimum number of battery cells $N_{\mathrm{BT} \text { min }}$ required to fulfill the driving cycle. This number can be determined from a battery sizing procedure based on the power flow model according to [23]. Finally, the constraint $g_{2}$ is expressed as

$$
g_{2}=N_{\mathrm{BT} \min }-\mathrm{NP}_{\mathrm{BT}} \times \mathrm{NS}_{\mathrm{BT}} \leq 0 .
$$

- Taking into account the elevated structure of choppers (from batteries toward bus) and of the maximum cyclic ratio $\alpha_{\max }$, the maximum voltage of a battery block $V_{\mathrm{BT} \max }$ must be then less than $\alpha_{\max } \times V_{\text {bus }}$. If the maximum voltage of a battery element is known, the constraint $g_{3}$ is written as follows:

$$
g_{3}=\mathrm{NS}_{\mathrm{BT}} V_{\mathrm{BT} \max }-\alpha_{\max } \times V_{\mathrm{bus}} \leq 0 .
$$

- If all previous constraints are satisfied, the locomotive sizing can be refined by evaluating the static converter volume $\Omega_{\mathrm{CBT}}$ associated with battery blocks. This volume can be computed from the driving cycle simulation by determining the maximum current in each battery block and, consequently, the filtering inductance required

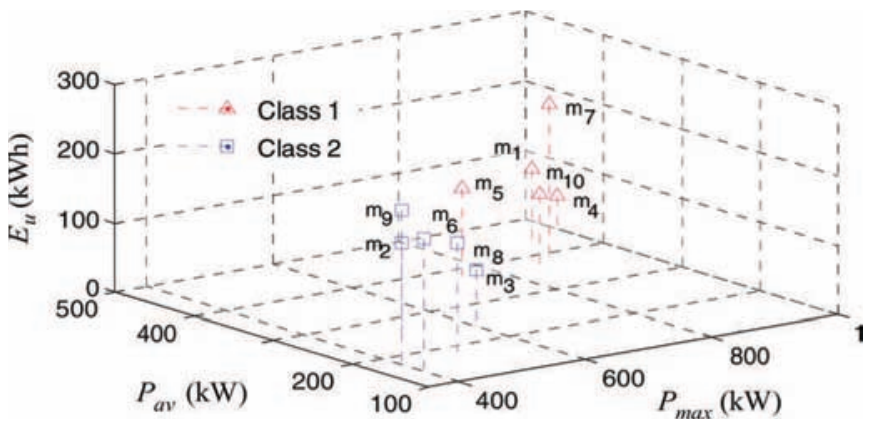

Fig. 11. Classification of railway profiles according to sizing indicators.

to limit the current ripples (see [35]). Finally, constraint $g_{4}$ can be expressed as

$$
g_{4}=\Omega_{\mathrm{BT}}+\Omega_{\mathrm{DE}}+\Omega_{\mathrm{CBT}}-32 \leq 0 .
$$

3) Optimization Criteria: The hybridization approach aims at minimizing the investment and usage costs and the environmental cost (tonnes of $\mathrm{CO}_{2}$ ). This systemic evaluation has been done with respect to a full Diesel locomotive of the same power. As the quantity of $\mathrm{CO}_{2}$ released is proportional to the quantity of fuel burn [see (10)], the environmental cost optimization can be therefore reflected in the optimization of the quantity of fuel burn. This enables us to reduce the multiobjective optimization problem into a single optimization problem consisting in the minimization of the annual total cost of ownership (TCO), integrating at the same time the costs of investment and usage (maintenance, lifetime, and fuel burn) as follows:

$$
\mathrm{TCO}=C_{\mathrm{DE}}+C_{\mathrm{BT}}+C_{\text {fuel }} .
$$

\section{Railway Profile Classification}

We move now to the classification of the railway driving cycles given in the Appendix according to the design indicators $\left\{P_{\max }, P_{\mathrm{av}}, E_{u}\right\}$. The result obtained by applying the RTSbased classification algorithm presented in Section III is shown in Fig. 11. It is shown that two different classes are obtained, each containing five elements.

\section{Synthesis of Representative Railway Profiles}

In this second study phase, we have applied the representative and compact profile synthesis process for each class $C_{1}$ and $C_{2}$, and for $C_{\Sigma}=\left(C_{1} \cup C_{2}\right)$, which is composed of the global set of profile. The reference indicators that enable the characterization of the representative profile are chosen as indicated in Section IV-B.

1) Class $C_{1}$ Representative Profile: $M_{1 \mathrm{rep}}$ : We set the duration of the representative profile for class $C_{1}$ at $4 \mathrm{~h}$, which corresponds to save a $1 / 5$ ratio over the total duration of concatenated profiles $(20 \mathrm{~h})$. The result of the synthesis process is given in Fig. 12(a). This representative profile $M_{1 \mathrm{rep}}$ is obtained through the concatenation of 125 segments and perfectly fulfills the reference indicators [see Table III and Fig. 12(b)].

2) Class $C_{2}$ Representative Profile: $M_{2 \mathrm{rep}}$ : The duration of the representative profile for class $C_{2}$ is set at $6 \mathrm{~h}$, which 


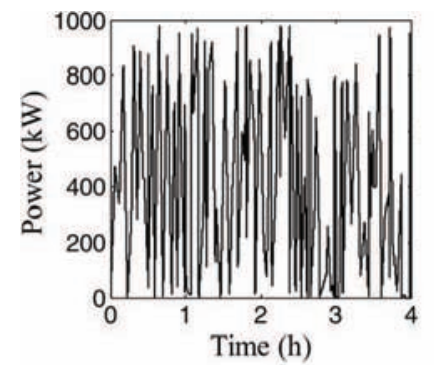

(a)

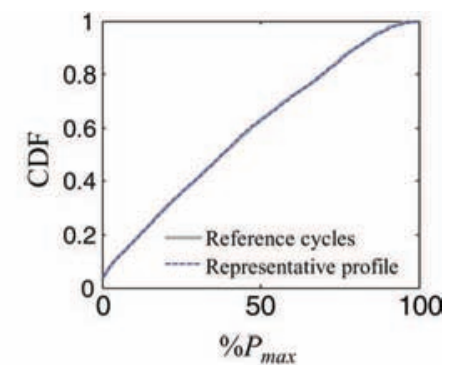

(b)
Fig. 12. Result of the compact profile synthesis process for class $C_{1}$. (a) Representative profile $M_{1 \mathrm{rep}}$ (b) Distribution functions.

TABLE III

CHARACTERIZATION INDICATORS OF THE REPRESENTATIVE PROFILE $M_{1 \mathrm{rep}}$

\begin{tabular}{cccc}
\hline \hline & Reference indicators & $\begin{array}{c}\text { Representative } \\
\text { profile indicators }\end{array}$ & Error (\%) \\
\hline$P_{\max }(\mathrm{kW})$ & 980 & 980 & $<10^{-2}$ \\
$P_{\text {av }}(\mathrm{kW})$ & 400 & 400 & $<10^{-2}$ \\
$E_{u t}(\mathrm{kWh})$ & 169.5 & 169.5 & $<10^{-2}$ \\
$N_{c_{-} \text {tot }}$ & 0.155 & 0.155 & $<10^{-2}$ \\
$\varepsilon_{\text {stat }}$ & - & - & 0.4 \\
\hline \hline
\end{tabular}

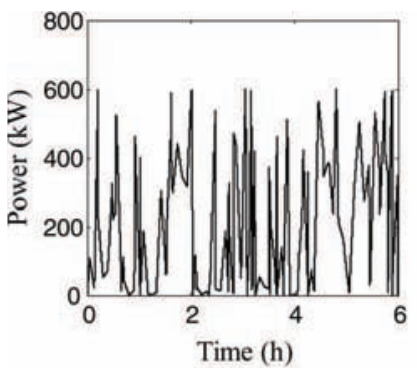

(a)

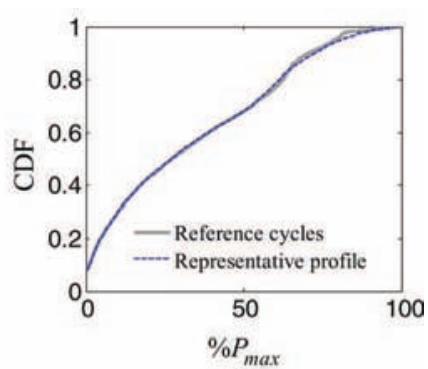

(b)
Fig. 13. Result of the compact profile synthesis process for class $C_{2}$. (a) Representative profile $M_{2 \mathrm{rep}}$ (b) Distribution functions.

TABLE IV

CHARACTERIZATION INDICATORS OF THE RePresentative Profile $M_{2 \text { rep }}$

\begin{tabular}{cccc}
\hline \hline & Reference indicators & $\begin{array}{c}\text { Representative } \\
\text { profile indicators }\end{array}$ & Error $(\%)$ \\
\hline$P_{\max }(\mathrm{kW})$ & 601 & 601 & $<10^{-2}$ \\
$P_{\mathrm{av}}(\mathrm{kW})$ & 200 & 201 & 0.5 \\
$E_{u}(\mathrm{kWh})$ & 194.5 & 194.5 & $<10^{-2}$ \\
$N_{\mathrm{c}_{-} \text {tot }}$ & 0.11 & 0.11 & $<10^{-2}$ \\
$\varepsilon_{\text {stat }}$ & - & - & 0.8 \\
\hline \hline
\end{tabular}

corresponds to save a ratio of $1 / 3.3$ over the total duration of concatenated profiles $(20 \mathrm{~h})$. The result of synthesis is given in Fig. 13(a). This representative profile $M_{2 \text { rep }}$ is obtained through the concatenation of 126 segments and perfectly fulfills the reference indicators [see Table IV and Fig. 13(b)].

3) Class $C_{\Sigma}$ Representative Profile: $M_{\Sigma \mathrm{rep}}$ : The representative and compact profile related to the set of ten driving cycles corresponds with the results presented in Section IV (see Fig. 6 and Table I).

\section{E. Integrated Design by Optimization}

Having determined the representative profiles, we proceed here to the integrated design of three hybrid locomotives that
TABLE $\mathrm{V}$

RESUlts OF DESIGN BY OptIMIZATION IN HYBRID LOCOMOTIVES

\begin{tabular}{|c|c|c|c|c|c|c|}
\hline \multirow[b]{2}{*}{ Variables } & \multicolumn{2}{|c|}{ Class $C_{1}$} & \multicolumn{2}{|c|}{ Class $C_{2}$} & \multicolumn{2}{|c|}{ Class $C_{\Sigma}$} \\
\hline & $L_{\text {lieal }}$ & $L_{\text {lrep }}$ & $L_{2 \text { real }}$ & $L_{\text {2rep }}$ & $L_{\text {Ereal }}$ & $L_{\sum \mathrm{rep}}$ \\
\hline $\mathrm{P}_{\mathrm{DI}}(\mathrm{kW})$ & 400 & 400 & 200 & 200 & 300 & 300 \\
\hline $\mathrm{NP}_{\mathrm{BT}}$ & 10 & 10 & 12 & 12 & 11 & 11 \\
\hline $\mathrm{NS}_{\mathrm{BT}}$ & 437 & 421 & 444 & 440 & 429 & 421 \\
\hline $\mathrm{N}_{\mathrm{BT}}$ & 4370 & 4210 & 5328 & 5280 & 4719 & 4631 \\
\hline $\mathrm{V}_{\text {bus }}(\mathrm{V})$ & 640 & 624 & 636 & 630 & 614 & 602 \\
\hline $\mathrm{F}_{\mathrm{SW}}(\mathrm{kHz})$ & 7.3 & 8.1 & 5.4 & 5.1 & 4.9 & 5.7 \\
\hline $\begin{array}{l}\mathrm{Q}_{\mathrm{CO}_{2}} \text { (tonnes } \\
\text { of } \mathrm{CO}_{2} / \mathrm{yr} \text { ) }\end{array}$ & 676 & 676 & 332 & 332 & 460 & 460 \\
\hline $\mathrm{TCO}(\mathrm{k} € / \mathrm{yr})$ & 397.2 & 398 & 202.8 & 203.1 & 318.5 & 319.6 \\
\hline$T_{\mathrm{c}}$ (days) & 5.7 & 1.2 & 5.7 & 1.6 & 10.4 & 3.8 \\
\hline
\end{tabular}

are optimized per profile class. Let $L_{1 \mathrm{rep}}, L_{2 \mathrm{rep}}$, and $L_{\Sigma \text { rep }}$ denote the hybrid locomotives, which are sized for classes $C_{1}$, $C_{2}$, and $C_{\Sigma}$, respectively, from representative railway profiles $M_{1 \text { rep }}, M_{2 \text { rep }}$, and $M_{\Sigma \text { rep }}$. To validate the consistency of the design results and to emphasize the synthesis process efficiency in terms of computation time, we have also sized three hybrid locomotives, which are optimized from a real profile class. In these cases, locomotives are designed in a "classical way" by considering the concatenation of all of the five driving cycles (instead of the corresponding compact and representative profile) under the hypothesis that the battery SOC is set to its initial value after each 4-h cycle. Thus, we also denote the hybrid locomotives sized for each class $C_{1}, C_{2}$, and $C_{\Sigma}$ from real complete cycles $M_{1 \text { real }}, M_{2 \text { real }}$, and $M_{\Sigma \text { real }}$, by $L_{1 \text { real }}$, $L_{2 \text { real }}$, and $L_{\Sigma \text { real }}$, respectively. Under the hypothesis that all initial profiles are realized with the same occurrence over a year with $8 \mathrm{~h}$ of use per day (two successive cycles per day) for each locomotive, the design results are given in Table V. The optimization algorithm used at the heart of the integrated design process is based on a GA and is coupled to the different hybrid locomotive models presented earlier.

The design results obtained for each profile class proves the effectiveness of the representative profile synthesis process in the system design approach. Indeed, we obtain practically nearly the same sizing from the hybrid locomotive by considering, on one hand, the fictitious representative profile, and, on the other hand, the concatenation of real profiles in the envisaged class. It should also be noted that the annual performance criteria ( $\mathrm{TCO}$ and $\mathrm{CO}_{2}$ emissions) estimated on the set of real profiles are equivalent. Finally, we mention in Table V the computational time $T_{c}$ required for the locomotive optimization in all investigated cases. It should be noted that all results were obtained from a GA run after 1000 generations using a population size of 100 individuals. Thus, $T_{c}$ is relative to the CPU time needed for those runs according to the driving profile used in the optimization process (i.e., the set of real driving cycles or the compact representative profile). We observe in Table $\mathrm{V}$ a significant saving in terms of CPU time between the two approaches. The synthesized representative profiles enable a computation saving, which is increased to 4.5 days for class $C_{1}, 4.1$ days for class $C_{2}$, and 6.6 days for class $C_{\Sigma}$. 


\section{F. Design Result Comparison}

Based on $8 \mathrm{~h} /$ day of use for each locomotive, the ten initial class $C_{\Sigma}$ profiles, with a total length of $40 \mathrm{~h}$, are repeated 73 times over the course of one year, whereas the five profiles in class $C_{1}$ of the same length are each repeated 146 times each year. To evaluate the interest in the classification (or segmentation), we compare the average annual costs of the two locomotives $L_{1}$ and $L_{2}$ with that of locomotive $L_{\Sigma}$ by considering the designs obtained with the representative and compact driving profiles. The average annual TCO of $L_{1}$ and $L_{2}$ is estimated at $\operatorname{TCO}\left(L_{1} \& L_{2}\right)=0.5 \times\left(\operatorname{TCO}\left(L_{1}\left(C_{1}\right)+\operatorname{TCO}\left(L_{2}\left(C_{2}\right)\right) \approx\right.\right.$ $300 \mathrm{k} € / \mathrm{yr}$ compared with $\operatorname{TCO}\left(L_{\Sigma}\right) \approx 320 \mathrm{k} € / \mathrm{yr}$, representing the annual TCO of a single locomotive $L_{\Sigma}$ performing all driving cycles. We observe that, for this ten-profile example, the design of two locomotives optimized per profile class enables a saving of $20 \mathrm{k} € / \mathrm{yr}(\sim 6 \%)$ compared with a single locomotive capable of satisfying all profiles on the list of specifications. Conversely, although it is less profitable financially, the single locomotive is better in terms of environment. Indeed, the annual use of this locomotive generates around 460 tonnes of $\mathrm{CO}_{2}$ versus $504 \mathrm{~T}$ of $\mathrm{CO}_{2}(\sim+9 \%)$ emitted during an average annual exploitation of both locomotives $L_{1}$ and $L_{2}$. The choice of whether to design a single locomotive or two different locomotives $L_{1}$ and $L_{2}$ is governed by a compromise between financial and ecological aspects. Beyond the result of this particular application, the interest of the complete approach (classification-profile synthesis-integrated optimal design) proposed in this paper is to facilitate the choice of design users, i.e., SNCF, in terms of segmentation of the product range and then sizing. These choices can be directly put forward into perspective with regard to the essential design criteria (i.e., ownership and climate costs).

\section{Conclusion}

In this paper, a systemic approach integrating driving cycles has been proposed for the design of hybrid autonomous locomotives. Efforts spent to achieve this process emphasize the prime importance of mission profile issues in HEVs and, more generally, of environmental variables for any class of systems.

This approach particularly exploits clustering analysis with the aim of identifying driving cycle classes that is relevant for market segmentation. Those classes are found using specific design indicators related to the driving cycle features and the propulsion hybrid system performance. Then, a synthesis procedure is applied to determine compact and representative profiles related to a given class or to a set of classes. Using the resulting profiles in the design process instead of the set of real driving cycles allows significant savings in computational time. It has been clearly shown through the application of the proposed design approach on the optimization of a hybrid autonomous locomotive devoted to shunting and switching operations. In addition, our approach also forms, for designer users, an "aid to market segmentation associated with an aid to system design." It can be extended to other kinds of systems without much difficulty, including standalone renewable energy systems and similar stochastic environmental variables (e.g., wind speed profiles).
APPENDIX

SET OF TEN DRIVING CYCLES OF A HyBRID Autonomous Locomotive Devoted to Shunting AND SWITCHING OPERATIONS
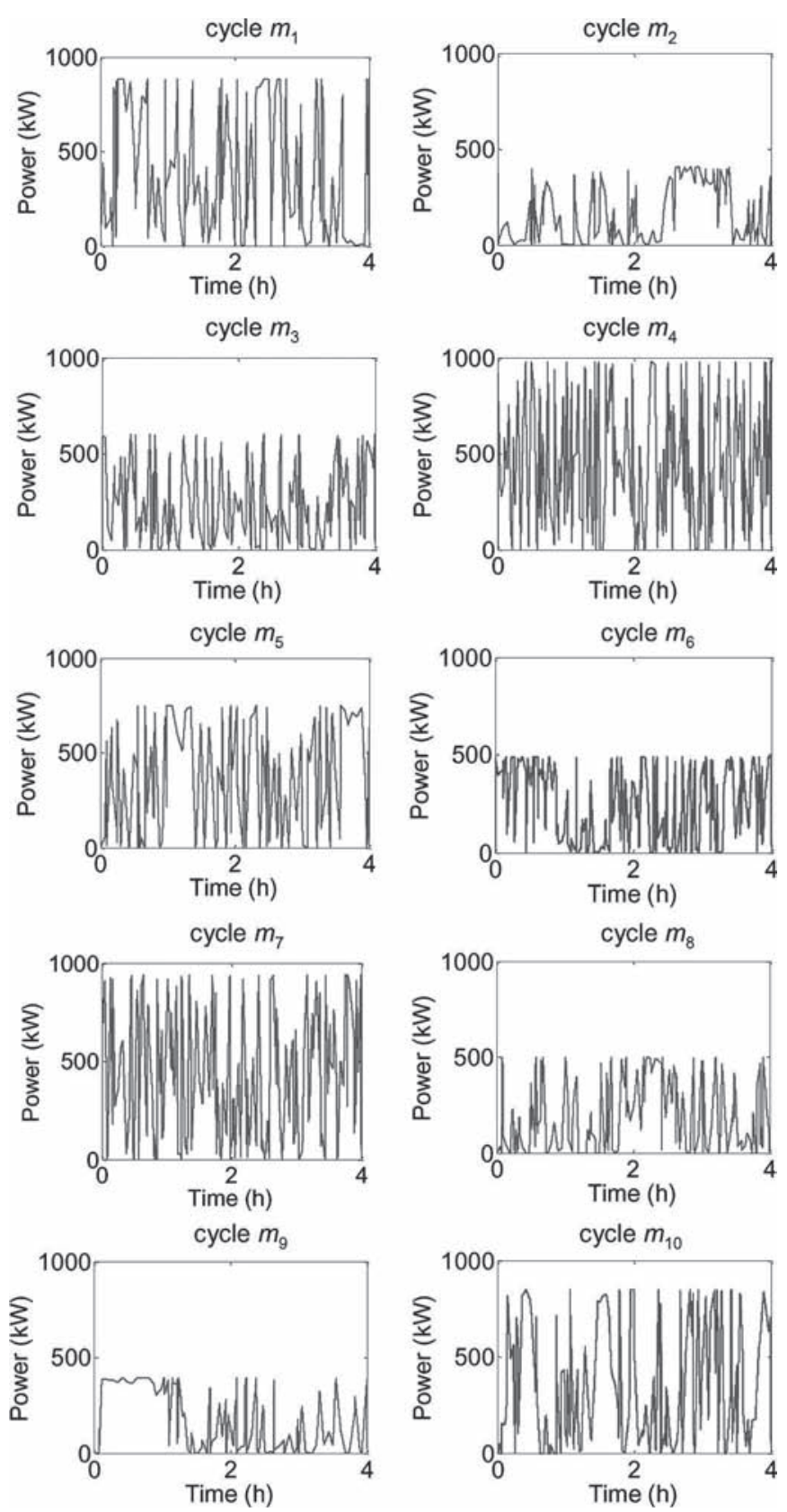

\section{REFERENCES}

[1] Emission Test Cycles for the Certification of Light Duty Vehicles in Europe, EEC Directive 90/C81/01 2009.

[2] H. Fan, G. E. Dawson, and T. R. Eastham, "Model of electric induction motor drive system," in Proc. IEEE Can. Conf. Elect. Comput. Eng., Sep. 14-17, 1993, vol. 2, pp. 1045-1048.

[3] A. Kleimaier and D. Schröder, "Optimization strategy for design and control of a hybrid vehicle," in Proc. 6th Int. Workshop Adv. Motion Control, Nagoya, Japan, 2000, pp. 459-464.

[4] S. Barsali, C. Miulli, and A. Possenti, "A control strategy to minimize fuel consumption of series hybrid electric vehicles," IEEE Trans. Energy Convers., vol. 19, no. 1, pp. 187-195, Mar. 2004.

[5] Emission Standards for Locomotives and Locomotive Engines; Final Rule, U.S. Environmental Protection Agency (EPA), 63 Federal Register 18978, 1998. 
[6] S. Zorrofi, S. Filizadeh, and P. Zanetel, "A simulation study of the impact of driving patterns and driver behavior on fuel economy of hybrid transit buses," in Proc. IEEE Veh. Power Propulsion Conf., Dearborn, MI, USA, 2009, pp. 572-577.

[7] B. A. Holmen and D. A. Niemeier, "Characterizing the effects of driver variability on real-world vehicle emissions," Transp. Res. Part D, vol. 3, no. 2, pp. 117-128, Mar. 1998.

[8] P. De Haan and M. Keller, "Real-world driving cycles for emission measurements: ARTEMIS and Swiss cycles," INFRAS, Zurich, Switzerland, BUWAL SRU Nr.255: Bern, 2001

[9] W. T. Hung, H. Y. Tong, C. P. Lee, K. Ha, and L. Y. Pao, "Development of practical driving cycle construction methodology: A case study in HongKong," Transp. Res. Part D, Transp. Environ., vol. 12, no. 2, pp. 115-128, Mar. 2007.

[10] E. Tara, S. Shahidinejad, S. Filizadeh, and E. Bibeau, "Battery storage sizing in a retrofitted plug-in hybrid electric vehicle," IEEE Trans. Veh. Technol., vol. 59, no. 6, pp. 2786-2794, 2010.

[11] M. André, "The ARTEMIS European driving cycles for measuring car pollutant emissions," Sci. Total Environ., vol. 334/335, pp. 73-84, Dec. 2004

[12] M. Andre, R. Joumard, R. Vidon, P. Tassel, and P. Perret, "Real-world European driving cycles, for measuring pollutant emissions from highand low-powered cars," Atmosp. Environ., vol. 40, no. 31, pp. 5944-5953, Oct. 2006.

[13] Q. Shi, D. Qiu, N. Wang, and R. Wang, "The impact analysis of the accuracy of driving cycle based on division of running statuses," in Proc. ICEICE, Wuhan, China, 2011, pp. 2767-2772.

[14] V. Schwarzer, R. Ghorbani, and R. Rocheleau, "Drive cycle generation for stochastic optimization of energy management controller for hybrid vehicles," in Proc. IEEE Int. Conf. Control Appl., Part IEEE Multi-Conf. Syst. Control, Yokohama, Japan, 2010, pp. 536-540.

[15] I. Kolmanovsky, I. Siverguina, and B. Lygoe, "Optimization of powertrain operating policy for feasability assessment and calibration: Stochastic dynamic programming approach," in Proc. IEEE Amer. Control Conf., Anchorage, AK, USA, 2002, vol. 2, pp. 1425-1430.

[16] P. Jiang, Q. Shi, W. Chen, Y. Li, and Q. Li, "Investigation of a new construction method of vehicle driving cycle," in Proc. 2nd ICITA, Changsha, China, 2009, pp. 210-214.

[17] C. C. Lin, H. Peng, and J. W. Grizzle, "A stochastic control strategy for hybrid electric vehicles," in Proc3 IEEE Amer. Control Conf., Boston, MA, USA, 2004, vol. 5, pp. 4710-4715.

[18] G. Ripaccioli, D. Bernardini, S. Di Cairano, A. Bemporad, and I. V. Kolmanovsky, "A stochastic model predictive control approach for series hybrid electric vehicle power management," in Proc. ACC, Baltimore, MD, USA, 2010, pp. 5844-5849.

[19] T. K. Lee and Z. S. Philipi, "Synthesis and validation of representative real-world driving cycles for plug-in hybrid vehicles," in Proc. IEEE Veh. Power Propulsion Conf., Lille, France, 2010, pp. 1-6.

[20] G. Souffran, L. Miegevielle, and P. Guérin, "Simulation of real-world vehicle missions using a stochastic Markov model for optimal design purposes," in Proc. IEEE VPPC, Chicago, IL, USA, Sep. 6-9, 2011, pp. $1-6$.

[21] X. Roboam, Ed., Integrated Design by Optimization of Electrical Energy Systems (ISTE). Hoboken, NJ, USA: Wiley, 2012.

[22] M. Ehsani, Y. Gao, and K. Butler, "Application of electrically peaking hybrid (ELPH) propulsion system to a full-size passenger car with simulated design verification," IEEE Trans. Veh. Technol., vol. 48, no. 6, pp. 17791787, Nov. 1999.

[23] C. R. Akli, X. Roboam, B. Sareni, and A. Jeunesse, "Energy management and sizing of a hybrid locomotive," in Proc. 12th EPE, 2007, pp. 1-10.

[24] S. Drouilhet and B. L. Johnson, "A battery life prediction method for the hybrid power applications," in Proc. 35th AIAA Aerosp. Sci. Meet. Exhib., 1997, pp. 1-14.

[25] R. Dufo-Lopez and J. L. Bernal-Agustin, "Multi-objective design of PVwind-diesel-hydrogen-battery systems," Renew. Energy, vol. 33, no. 12, pp. 2559-2572, Dec. 2008

[26] A. Jaafar, C. R. Akli, B. Sareni, X. Roboam, and A. Jeunesse, "Sizing and energy management of a hybrid locomotive based on flywheel and accumulators," IEEE Trans. Veh. Technol., vol. 58, no. 8, pp. 3947-3958, Oct. 2009

[27] S. H. Baek, S. S. Cho, and W. S. Joo, "Fatigue life prediction based on the rainflow cycle counting method for the end beam of a freight car bogie," Int. J. Automotive Technol., vol. 9, no. 1, pp. 95-101, Feb. 2008.
[28] [Online]. Available: http://www.hoppecke.com, 2012

[29] A. Jaafar, B. Sareni, and X. Roboam, "Clustering analysis of railway driving missions with niching," Int. J. Comput. Math. Elect. Electron. Eng. (COMPEL), vol. 31, no. 3, pp. 920-931, 2012.

[30] G. Harik, "Finding multimodal solutions using restricted tournament selection," in Proc. 6th Int. Conf. Genetic Algorithms, 1995, pp. 24-31.

[31] B. Sareni, J. Régnier, and X. Roboam, "Recombination and selfadaptation in multi-objective genetic algorithms," in Proc. Artif. Evolution, vol. 2936, Lecture Notes in Computer Science, 2004, pp. 115-126.

[32] P. J. Rousseeuw, "Silhouettes: A graphical aid to the interpretation and validation of cluster analysis," Comput. Appl. Math., vol. 20, pp. 53-65, Nov. 1987.

[33] A. Petrowski, "A clearing procedure as a niching method for genetic algorithms," in Proc. IEEE Int. Conf. Evolutionary Computation, Nagoya, Japan, 1996, pp. 798-803.

[34] A. Jaafar, B. Sareni, and X. Roboam, "Signal synthesis by means of evolutionary algorithms," Inverse Probl. Sci. Eng., vol. 20, no. 12, pp. 93104, Jan. 2012.

[35] C. R. Akli, X. Roboam, B. Sareni, and A. Jeunesse, "Integrated optimal design of a hybrid locomotive with multiobjective genetic algorithms," Int. J. Appl. Electromagn. Mech., vol. 4, no. 3/4, pp. 151-162, 2009.

[36] [Online]. Available: http://www.fptindustrial.com, 2012

[37] L. A. Graham, "Greenhouse gas emissions from light duty vehicles under a variety of driving conditions," in Proc. IEEE EIC Climate Change Technol., 2006, pp. 1-8.

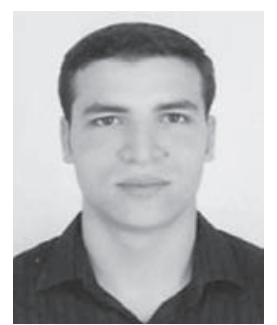

Amine Jaafar was born in Sousse, Tunisia, in 1983. $\mathrm{He}$ received the Engineering degree in electrical engineering from Ecole Nationale d'Ingénieur de Monastir, Monastir, Tunisia, in 2007 and the Ph.D. degree from the University of Toulouse, Toulouse, France, in 2011. He is currently working as assistant professor with INP-ENSEEIHT, Toulouse, France, where he is studying fuel cell applications as a researcher with the Laboratory on Plasma and Conversion of Energy (LAPLACE).

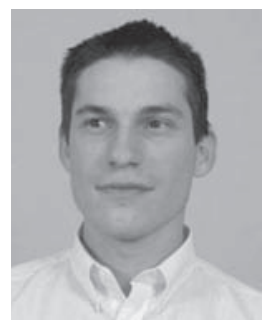

Bruno Sareni was born in Bron, France, in 1972. He received the Ph.D. degree from Ecole Centrale de Lyon, Écully, France, in 1999.

$\mathrm{He}$ is currently a Professor in electrical engineering and control systems with the National Polytechnic Institute of Toulouse, Toulouse, France. He is also a Researcher with the Laboratory on Plasma and Conversion of Energy (LAPLACE), University of Toulouse, Toulouse. His research interests include the analysis of complex heterogeneous power devices in electrical engineering and the optimization of these systems using artificial evolution algorithms.

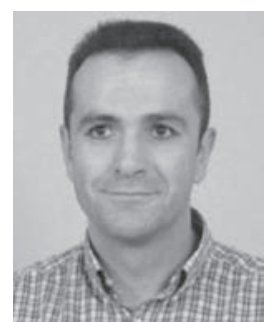

Xavier Roboam received the Ph.D. degree in electrical engineering from the University of Toulouse, Toulouse, France, in 1991.

Since 1992, he has been with the Laboratory on Plasma and Conversion of Energy, University of Toulouse, as a Full-Time Researcher. Since 1998, has been the Head of the Research Group in Electrical Energy and Systemics (GEnESys), whose objective is to process the design problem in electrical engineering at a "system level." He has developed methodologies specifically oriented toward multifield system design for applications such as electrical embedded systems or renewable energy systems. 